\title{
ENHANCING IN SITU BIOREMEDIATION WITH PNEUMATIC FRACTURING
}

D. B. Anderson

B. M. Peyton

J. L. Liskowitz

C. Fitzgerald

J. R. Schuring

April 1994

Presented at the

In Situ and On-Site Bioreclamation: The Third International

Symposium Proceedings

April 24-27, 1994

San Diego, California

Prepared for

the U.S. Department of Energy

under Contract DE-AC06-76RLO 1830

Pacific Northwest Laboratory

Richland, Washington 99352
DISTRIBUTION OF THIS DOCUMENT IS UNUMITEO "ISTRBBUTION OF THIS DC 


\section{DISCLAIMER}

Portions of this document may be illegible in electronic image products. Images are produced from the best available original document. 
Enhancing In Situ Bioremediation with Pneumatic Fracturing

Daniel B. Anderson, Brent M. Peyton, John J. Liskowitz, Conan Fitzgerald, and John R. Schuring

\section{ABSTRACT}

A major technical obstacle affecting the application of in situ bioremediation is the effective distribution of nutrients to the subsurface media. Pneumatic fracturing can increase the permeability of subsurface formations through the injection of high pressure air to create horizontal fracture planes, thus enhancing macro-scale mass-transfer processes. Pneumatic fracturing technology was demonstrated at two field sites at Tinker Air Force Base, Oklahoma City, Oklahoma. Tests were performed to increase the permeability for more effective bioventing, and evaluated the potential to increase permeability and recovery of free product in low permeability soils consisting of fine grain silts, clays, and sedimentary rock. Pneumatic fracturing significantly improved formation permeability by enhancing secondary permeability and by promoting removal of excess soil moisture from the unsaturated zone. Postfracture airflows were $500 \%$ to $1,700 \%$ higher than prefracture airflows for specific fractured intervals in the formation. This corresponds to an average prefracturing permeability of 0.017 Darcy, increasing to an average of 0.32 Darcy after fracturing. Pneumatic fracturing also increased free-product recovery rates of number 2 fuel from an average of $587 \mathrm{~L}$ ( $155 \mathrm{gal}$ ) per month before fracturing to $1,647 \mathrm{~L}$ ( $435 \mathrm{gal})$ per month after fracturing.

\section{INTRODUCTION}

In situ bioremediation has great potential to clean large volumes of soil and groundwater; however, the process is plagued by the lack of ability to effectively distribute nutrients throughout the 
contaminated area. This limitation often controls both the rate and extent of the cleanup effort by significantly reducing the amount of nutrients or microbes that can be delivered to the subsurface environment. Integrating in situ bioremediation with "enabling technologies" can increase the number of sites where bioremediation can be applied.

One such enabling technology is pneumatic fracturing $(\mathrm{PF})$. The PF process may be generally described as injecting air into a contaminated geologic formation at a pressure that exceeds the natural strength of the formation. The resulting failure of the medium creates a fracture network radiating from the injection point, which increases the formation's macro-scale permeability. Once established, the fractures increase the rate at which vapors or liquids can travel through the formation and thereby make the contaminants more accessible to remediation. This results in a greater distribution and radius of influence for each nutrient injection or contaminant extraction well. For formations containing significant amounts of silt and clay, the process creates new convective pathways in the formation, which increase permeability and shorten the distance nutrients must travel to reach contaminated soils. In sedimentary rock formations, such as sandstone and shale, the process dilates and extends existing discontinuities and thereby increases permeability and improves interconnectivity. The technology has been applied in both the unsaturated and saturated zones of contaminated formations (Liskowitz et al. 1993). A recent modification of the pneumatic fracturing system permits delivery of biological supplements (e.g., nutrients, buffers, and microorganisms) directly into the fractured formation to enhance in situ bioremediation (Fitzgerald 1993). When injection of microbes is necessary, for example when specialized contaminant-degrading organisms are used, $\mathrm{PF}$ can overcome some of the associated problems. The conventional method for injection of bacteria into the subsurface can lead to filtration and the formation of a "biofilm" at the point of injection. This biofilm can foul the injection well to the point that no further injection is possible without costly well-cleaning procedures. Delivery of bacteria during pneumatic fracturing will significantly improve injection and distribution of microorganisms in the subsurface. 
15, 1993. The objective was to apply $P F$ at two separate locations and evaluate its ability to enhance remediation activities in the low-permeability formations at the base. Data are presented on the ability of PF to increase soil permeability in the field. The project was sponsored by the United States Department of Energy (U.S. DOE) and the United States Air Force (USAF).

\section{FIELD TESTS AND OBSERVATIONS}

\section{Southwest Tanks Site}

At the Southwest Tanks Site (STS), the superficial soils in the test zone consisted principally of clayey silt [approx. $3 \mathrm{~m}(10 \mathrm{ft})$ ], grading to silt and silty sand with increasing depth. A perched water table was located approximately $5.5 \mathrm{~m}$ (18 ft) below the ground surface. Previous laboratory analyses show that soil permeabilities ranged from $10^{-7} \mathrm{~cm} / \mathrm{s}$ in the clay layer to $10^{-5} \mathrm{~cm} / \mathrm{s}$ in the silty sand layers. Past operations of an underground storage tank (UST) complex for fuels and waste oil at this site resulted in free floating product and extensive soil contamination with total petroleum hydrocarbons (TPHs) and benzene, toluene, ethylbenzene, and xylenes (BTEX).

Free product removal and bioventing were the preferred technologies for the STS remediation. Fracturing tests were done to determine the effect of $\mathrm{PF}$ on the formation permeability and to determine if extraction of volatile organic compounds (VOCs) would improve significantly after fracturing. Injection pressures ranged from $1.52 \times 10^{7}$ to $5.07 \times 10^{7} \mathrm{~Pa}(150$ to $500 \mathrm{PSI})$. The injections lasted from 10 to 30 seconds resulting a total injected air volume of 10.6 to $22.7 \mathrm{~m}^{3}$ at STP (375 to $800 \mathrm{SC}$.). The effects of fracturing were measured as surface heave (the vertical rise at the ground surface) and an increase in the vacuum radius of influence. Fracture injections were made in two different zones: six shallow injections in the depth range from 1.8 to $3.7 \mathrm{~m}$ ( 6 to $12 \mathrm{ft}$ ); and one injection 5.5 to $6.1 \mathrm{~m}$ (18 to $20 \mathrm{ft}$ ) deep. Surface heave measurements, which reflect the extent of fracture propagation, generally agreed with the radii 
observed in vacuum tests. Figure 1 shows surface heave contours during the fracturing process; maximum heave was just over $1.3 \mathrm{~cm}(0.5 \mathrm{in})$, and measurable radius of influence exceeded $6.1 \mathrm{~m}(20 \mathrm{ft})$.

For bioventing applications, the vacuum radius of influence is often used as an important determinant of well spacing. Prefracturing and postfracturing vacuum radii of influence are shown in Figure 2. Fracturing significantly increased the volume of soil that can be reached with a given bioventing well.

Helium tracer tests were performed at the STS, but tracer arrival times did not differ substantially between the prefracture and postfracture conditions. Helium was also detected in all soil gas samples taken from piesometers in $1 \mathrm{ft}$ depth intervals (data not shown). The data suggest that evenly distributed natural fractures were already present at the site. Modeling was used to show that oxygen diffusion from the fractures would be sufficient for application of biorenting techniques for remediation. A possible explanation for the discrepancy between the helium test results and the vacuum permeability results may lie in the differing test modes. The helium tracer was injected under a positive pressure, and the air extraction tests were conducted under vacuum conditions. The vacuum tests may draw excess moisture from the unsaturated formation into the fractures, effectively sealing them off to gas flow:

Vapor extraction tests were conducted over 21 days in the shallow fracture zone. Postfracture airflows were $500 \%$ to $1,700 \%$ higher than prefracture airflows for specific fractured intervals in the formation. This corresponds to an average prefracturing permeability of 0.017 Darcy, increasing to an average of 0.32 Darcy after fracturing. In combined vapor injection and extraction tests conducted in the deep fracture zone over a period of 17 days, with sealed monitoring wells, postfracture airflows increased $150 \%$. When the test was continued with unsealed monitoring wells, airflow enhancement ranged between $500 \%$ and $1,000 \%$, suggesting substantial connection with outlying wells. The corresponding average permeability increased from 0.026 Darcy prefracture to 0.142 Darcy after fracturing.

It should be noted that, permeability increases can lead to a significant improvement in the mass flow rate of air that can be delivered through a given well. However, the number and distribution of 
fractures will determine the oxygen delivery rate to specific regions of the vadose zone. An overall increase in the air flow rate cannot guarantee that oxygen has reached all locations of the contaminated region.

North Tank Area

At the North Tank Area (NTA), an operational unit associated with a 1990 Record of Decision (COE 1990) for building 3001, UST 3404, which was used to store \#2 fuel oil, had released petroleum hydrocarbons into the subsurface. Interim remedial actions included installing a floating product removal system, removing and disposing of the other tanks at the site, and conducting in situ treatability studies to evaluate the potential of bioventing to treat residual contaminated soils. Additional site inrestigations conducted in 1992 resulted in the development of a conceptual site model suggesting stratification of the perched water system as shown in Figure 3. These studies also suggested that a significant portion of the product was trapped beneath an upper confining shale unit 5.2 to $7.6 \mathrm{~m}$ (17 to $23 \mathrm{ft}$ ) beneath the surface. The base of the tank appears to rest near the base of the upper shale unit, and excavation during installation of the tank most likely disrupted this shale layer. Because of this and the positive differential pressure that would exist between Tank 3404 and the groundwater when the tank was filled, fuel oil was most likely chronically pushed into these permeable units, predominately the lower sandstone. To remove the free product beneath the tank, four recovery wells were installed along the perimeter of the tank. Although significant amounts of free product were present in the wells initially, the recharge rates and product recovery over nearly 2 years were limited.

Pneumatic fracturing was tested to help improve the rate of free product recover: by producing fractures to connect an existing recovery well (RC-4) with the free product trapped below the upper shale unit. Enhanced free product recovery would be the essential first step in an integrated remediation scheme with bioventing processes to biodegrade the residual soil contamination in a timely fashion. A deep 
pneumatic fracturing injection was conducted in the saturated zone in a newly installed fracturing well, NTA-4, between the tank and RC-4. Injection pressures ranged from $1.52 \times 10^{7}$ to $5.07 \times 10^{7} \mathrm{~Pa}(150$ to 500 PSI). The injections lasted from 10 to 30 seconds resulting a total injected air volume of 10.6 to $22.7 \mathrm{~m}^{3}$ at STP ( 375 to $800 \mathrm{SCF})$. The fracture interval, 7.9 to $8.5 \mathrm{~m}(26$ and $28 \mathrm{ft}$ ) below ground surface, was immediately below the upper confining shale unit. The pneumatic injection at NTA-4 connected with at least seven wells besides RC-4. Pneumatic connection became apparent when the outlying wells became pressurized after completion of the deep injection. The farthest connection was RC-2, approximately 18.3 $\mathrm{m}(60 \mathrm{ft})$ from the injection point.

A baildown test was performed in RC-4 to quantify the increase in product recovery. During the prefracture component of the test, the static product thickness was $0.5 \mathrm{~m}(1.5 \mathrm{ft})$, with about a $200-\mathrm{h}$

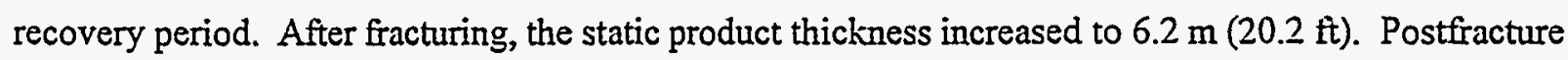
equilibrium was obtained $75 \mathrm{~h}$ after baildown, and $76 \mathrm{~L}$ ( $20 \mathrm{gal}$ ) of free product recharged into the well during the $22 \mathrm{~h}$ after evacuation. After the pneumatic fracturing demonstration, the Air Force resumed product recovery at the NTA. Figure 4 summarizes the recovery data for August 1993 through June 1994, which includes total product removed. Product recovery increased from an average of $587 \mathrm{~L}$ (155 gal) per month for all the wells in the North Tank Area before fracturing to 1,647 L (435 gal) per month after fracturing for only two wells. The gradual decline in postfracture recovery rates is at least partly attributable to depletion of product near the well, to a gradual deterioration of the fracture network, or both. Another factor that may explain the decline in recovery rate is related to site operations; the recovery wells were shut down for extended periods after fracturing for site characterization and system maintenance.

\section{SUMMARY}

Pneumatic fracturing significantly improved formation permeability by enhancing secondary 
permeability and by promoting removal of excess soil moisture from the unsaturated zone. Results of these field tests show that PF may provide enhancements to situ bioremediation processes, including (1) increased permeability for faster delivery of air in bioventing applications, (2) improved free product recovery. Pneumatic fracturing could also be used to deliver biological supplements (e.g., nutrients, buffers, and microorganisms) directly into the fractured formation to enhance in situ bioremediation.

\section{ACKNOWLEDGMENTS}

Pacific Northwest Laboratory is operated for the U. S. Department of Energy by Battelle Memorial Institute under contract DE-AC06-76RLO 1830.

\section{REFERENCES}

COE 1990. Building 3001 (NPL Site) Record of Decision. U.S. Army Corps of Engineers (COE), Tulsa District, Tinker AFB, Oklahoma City, OK.

Fitzgerald, C.D. 1993. "Integration of Pneumatic Fracturing to Enhance In Situ Bioremediation." Master's thesis, New Jersey Institute of Technology, Newark, NJ.

Liskowitz, J.J., J.R. Schuring, and J. Mack. 1993. "Application of Pneumatic Fracturing Extraction for the Effective Removal of Volatile Organic Compounds in Low Permeability Formations." Presented at the Focus Conference on Eastern Groundwater Issues, National Groundwater Association, Sept. 1993, Burlington, VT. 
Keywords - pneumatic fracturing, nutrient injection, permeability, free product.

Figure captions

FIGURE 1.

Typical surface heave contours measured during the fracturing process.

FIGURE 2.

Typical increase in vacuum radius of influence as a result of pneumatic fracturing. Contours are in $\mathrm{cm}$ of water.

FIGURE 3. Schematic diagram of the stratified geology and perched aquifer system at the North Tank Area.

FIGURE 4. Product recovery data for the North Tanks Area before and after pneumatic fracturing. 


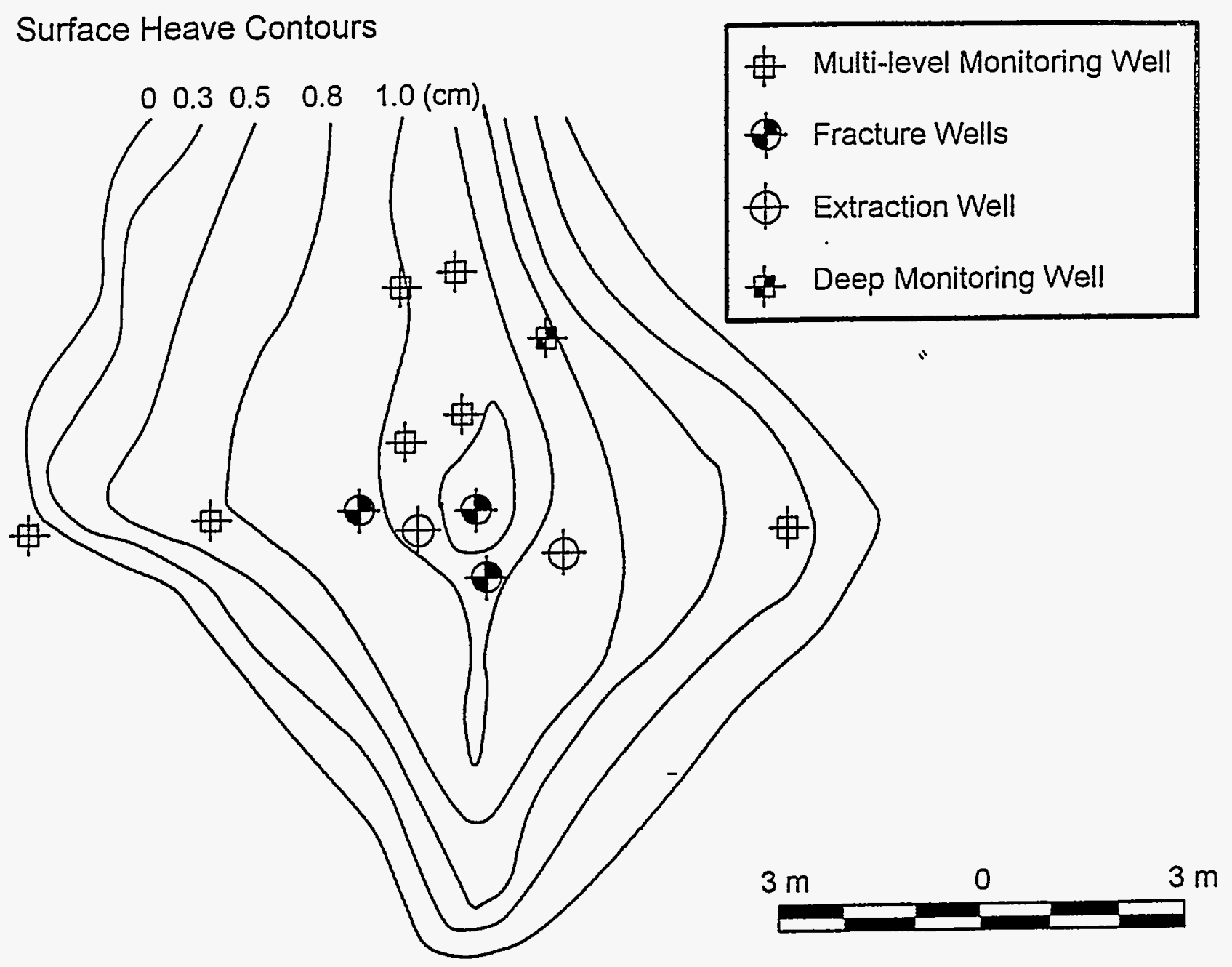



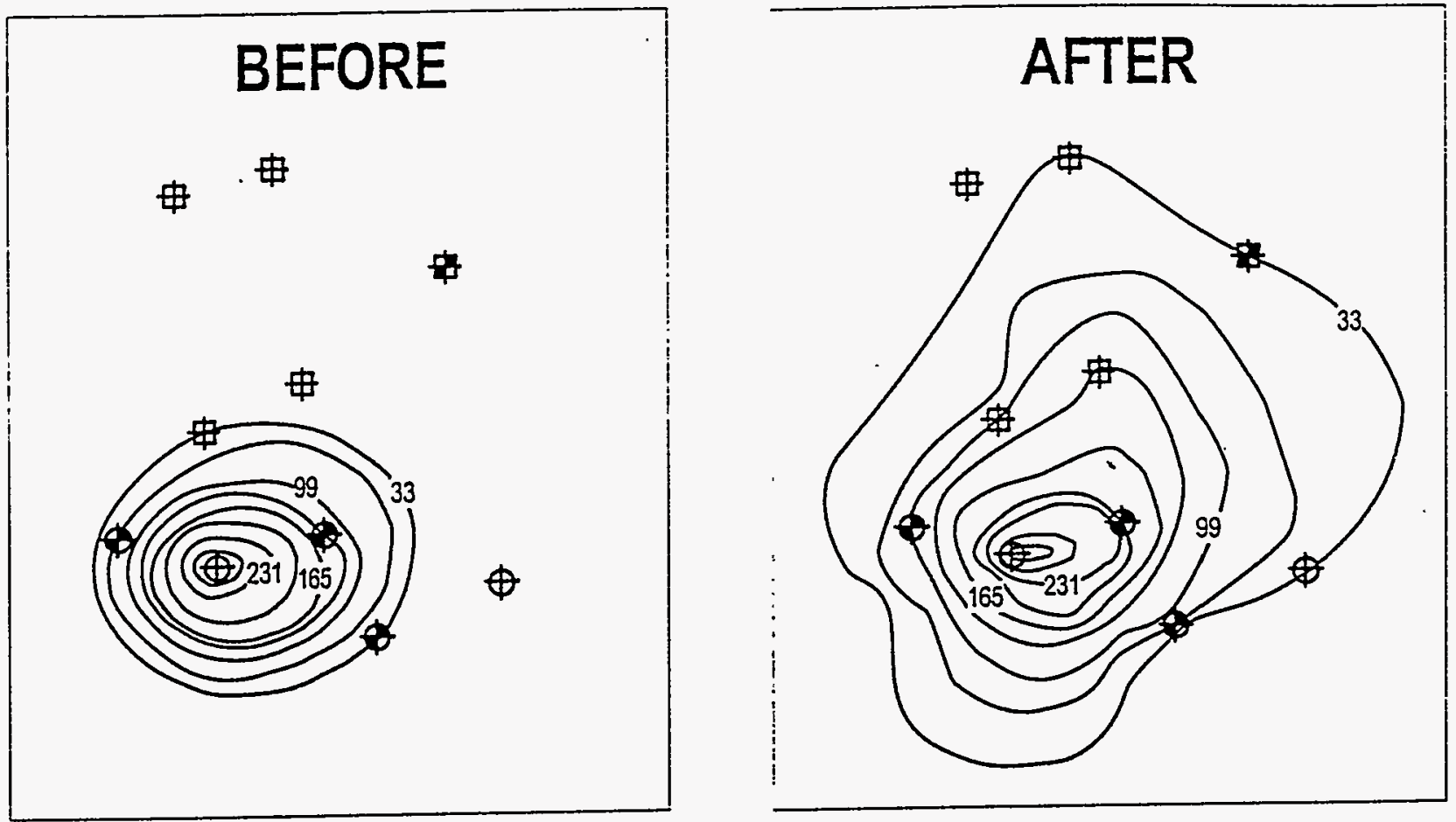

\section{中ulti-level Monitoring Well $\bigoplus$ Extraction Well




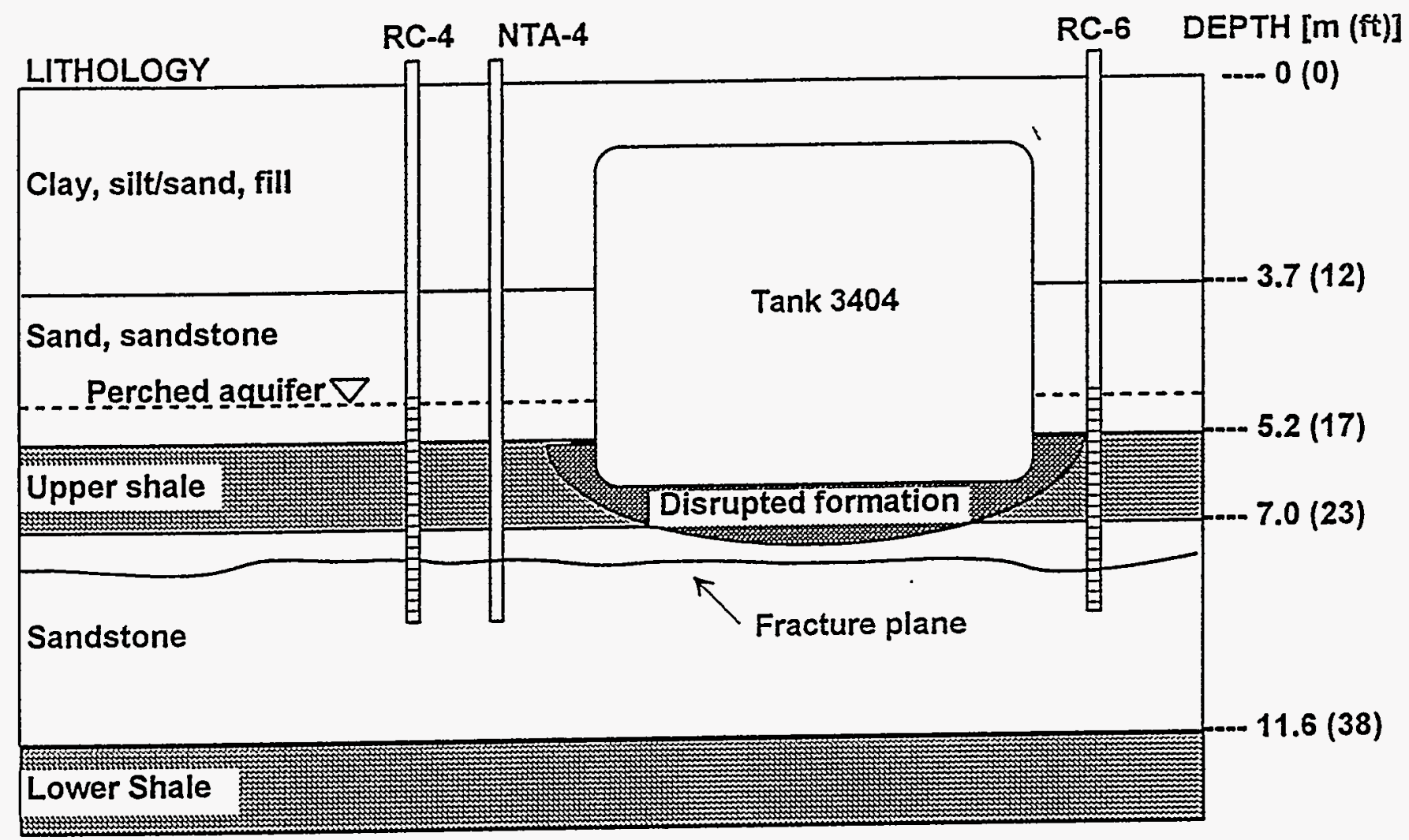




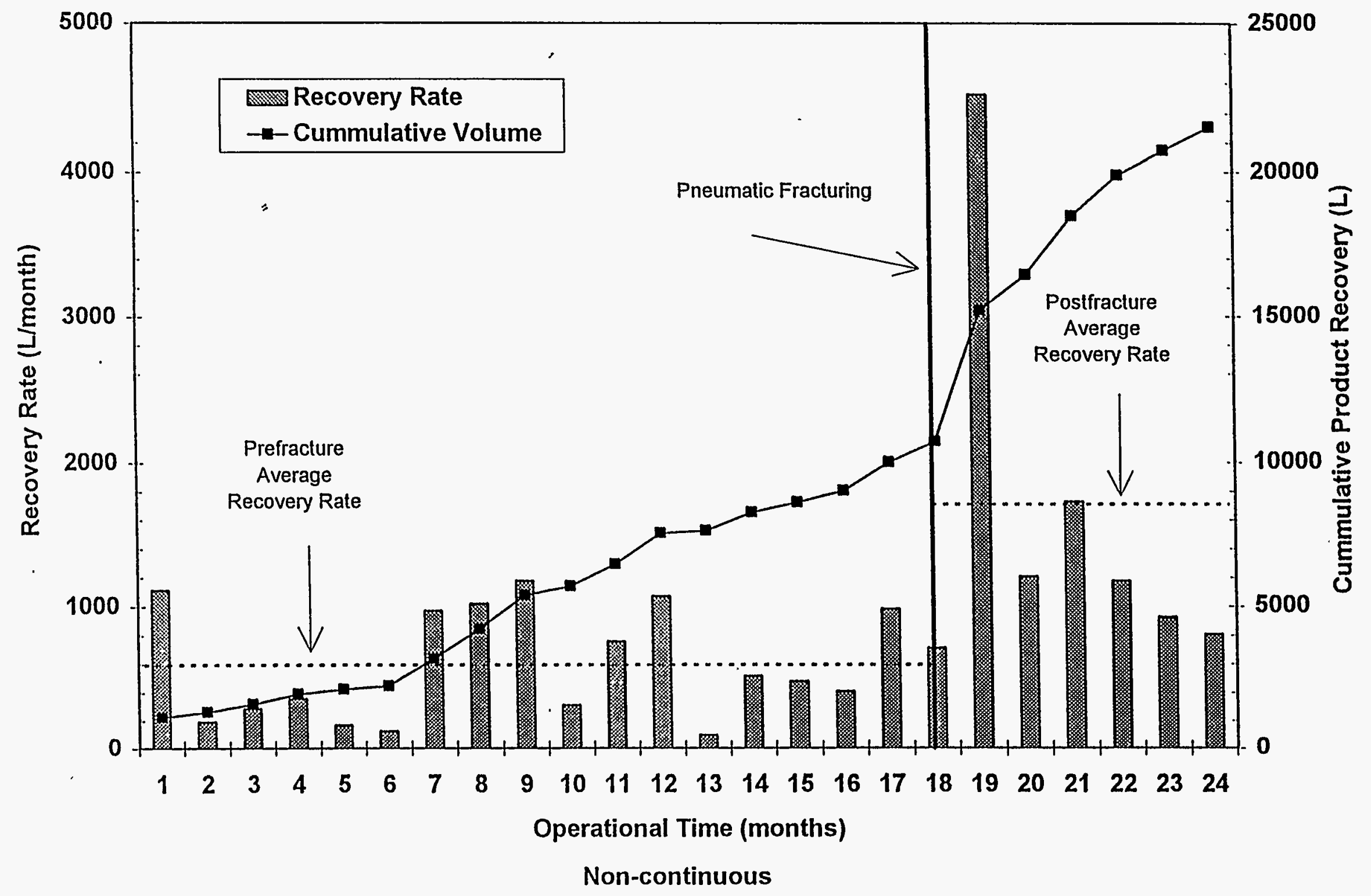

